\title{
Energy Conservation in Ethanol-Water Distillation Column with Vapour Recompression Heat Pump
}

\author{
Christopher Enweremadu \\ University of South Africa, Florida Campus \\ South Africa
}

\section{Introduction}

Ethanol or ethyl alcohol $\mathrm{CH}_{3} \mathrm{CH}_{2} \mathrm{OH}$, a colorless liquid with characteristic odor and taste; commonly called grain alcohol has been described as one of the most exotic synthetic oxygen-containing organic chemicals because of its unique combination of properties as a solvent, a germicide, a beverage, an antifreeze, a fuel, a depressant, and especially because of its versatility as a chemical intermediate for other organic chemicals. Ethanol could be derived from any material containing simple or complex sugars. The sugar-containing material is fermented after which the liquid mixture of ethanol and water is separated into their components using distillation.

Distillation is the most widely used separation operation in chemical and petrochemical industries accounting for around $25-40 \%$ of the energy usage. One disadvantage of distillation process is the large energy requirement. Distillation consumes a great deal of energy for providing heat to change liquid to vapour and condense the vapour back to liquid at the condenser. Distillation is carried out in distillation columns which are used for about $95 \%$ of liquid separations and the energy use from this process accounts for an estimated $3 \%$ of the world energy consumption (Hewitt et al, 1999). It has been estimated that the energy use in distillation is in excess. With rising energy awareness and growing environmental concerns there is a need to reduce the energy use in industry. The potential for energy savings therefore exists and design and operation of energy efficient distillation systems will have a substantial effect on the overall plant energy consumption and operating costs.

The economic competitiveness of ethanol has been heightened by concerns over prices and availability of crude oil as well as greenhouse gas emissions which have stimulated interest in alternatives to crude oil to provide for automotive power and also by the use of bioethanol in the production of hydrogen for fuel cells. Therefore, there is the need to explore ways of producing ethanol at competitive costs by the use of energy efficient processes. To cope with the high energy demand and improve the benefits from the process, the concept of polygeneration and hydrothermal treatment especially when dealing with small scale ethanol plants is fast gaining interest. However, the analysis of the bioethanol process shows that distillation is still the most widely used. 
Over the years, there have been many searches for lower energy alternatives or improved efficiencies in distillation columns. One such search led to the use of heat pumps, the idea which was introduced in the 1950s. Also, Jorapur and Rajvanshi (1991) have used solar energy for alcohol distillation and concluded that it was not economically viable. Heat pumping, however, has been known as an economical energy integration technology for reduction in consumption of primary energy and to minimize negative impact of large cooling and heating demands to the environment. One of the heat pump cycles which have been widely studied is the recompression of the vapours where the reboiler is heated by adding a compressor to the column to recover some of the heat lost in the distillate.

Most studies have concluded that heat pumping is an effective means of saving energy and reducing column size without estimating the actual energy consumption and the parameters that are likely to have significant effect on energy consumption. Estimating the actual energy consumption is an important aspect towards the determination of the viability of the system in ethanol-water separation.

The purpose of this chapter was to study how previously neglected and/or assumed values of different parameters (the pressure increase across the compressor was ignored, column heat loss was assumed to be $10 \%$ of the reboiler heat transfer rate, and the overall heat transfer coefficient was determined without considering it as an explicit function of dimensionless numbers, and its dependence on fluid viscosity and thermal conductivity neglected) affect the process efficiency, energy consumption and the column size of a vapour recompression heat pump.

\section{Energy requirements in ethanol distillation}

Ethanol distillation, like any other distillation process requires a high amount of thermal energy. Studies carried out by several authors reveal that the distillation process in ethanol distilleries consumes more than half of the total energy used at the distillery (Pfeffer et al. 2007). It has been estimated that distillation takes up about $70-85 \%$ of total energy consumed in ethanol production. Pfeffer et al (2007) estimated that distillation consumes half of the total production energy 5.6 MJ/Liter out of $11.1-12.5 \mathrm{MJ} /$ Liter.

The energy requirements for ethanol production have improved markedly during the past decade due to a variety of technology and plant design improvements. The energy needed to produce a liter of ethanol has decreased nearly $50 \%$ over the past decade and that trend is likely to continue as process technology improves (Braisher et al, 2006).

\section{Energy conservation schemes in distillation column}

Distillation columns are usually among the major energy-consuming units in the food, chemical, petrochemical and refining industries. According to Danziger (1979), the most effective method of economizing energy in a distillation column is energy recovery of which direct vapour recompression has been regarded as the best solution.

\subsection{Heat pumping distillation systems}

Basically, the heat pump can be regarded simply as reverse heat engine. The heat pump requires either work input or external driving thermal energy to remove the heat from a low temperature source and transform it to a higher level. 
The conventional heat pumps are electrically driven vapour recompression types, which work on the principle that a liquid boils at a higher temperature if its pressure is increased. A low-pressure liquid passes into the evaporator, where it takes in heat causing the liquid to boil at low temperature. The low-pressure vapour is passed to the compressor where it is compressed by the application of work to a higher pressure. The resulting high pressure vapour flows to the condenser where it condenses, giving up its latent heat at a high temperature, before expanding back to a low pressure liquid.

The heat pump cycle may be connected to a distillation column in three ways (Fonyo and Benko, 1998). The simplest alteration is to replace steam and cooling water with refrigerant (closed system). The other two types of heat pump system apply column fluids as refrigerant. When the distillate is a good refrigerant the vapour recompression can be used. If the bottom product is a good refrigerant the bottom flashing can be applied.

In this work, the direct vapour recompression system is studied due to its good economic figures (Emtir et al, 2003). Also the vapour recompression is the most suitable as the boiling points of both key components (ethanol and water) are close to each other (Danziger, 1979) and the appropriate heat transfer medium (ethanol vapour) is available.

\subsection{Use of vapour recompression in distillation columns}

Vapour recompression system has been extensively studied since 1973, the year of drastic rise in energy (Null, 1976). The vapour recompression system is accomplished by using compressor to raise the energy level of vapour that is condensed in reboiler-condenser by exchange of heat with the bottoms. The condensate distillate is passed into reflux drum while the bottom product is vaporised into the column.

Vapour recompression consists of taking the overhead vapour of a column, condensing the vapour to liquid, and using the heat liberated by the condensation to reboil the bottoms liquid from the same column. The temperature driving force needed to force heat to flow from the cooler overhead vapours to the hotter bottoms product liquid is set up by either compressing the overhead vapour so that it condenses at a higher temperature, or lowering the pressure on the reboiler liquid so it boils at a lower temperature, then compressing the bottoms vapour back to the column pressure. While conventional column has a separate condenser and reboiler, each with its own heat transfer fluid such as cooling water and steam, the vapour recompression column has a combined condenser-reboiler, with external heat transfer fluids.

The advantage of vapour recompression lies in its ability to move large quantities of heat between the condenser and reboiler of the column with a small work input. This results from cases where there is only a small difference between the overhead and bottoms temperature. Also, the temperature, and therefore the pressure, at any point may be set where desired to achieve maximum separation. This effect is of particular importance where changing the pressure affects the relative volatility. By operating at more favourable conditions, the reflux requirement can be reduced and therefore the heat duties. These advantages can reduce a large amount of energy.

\section{Ethanol-water vapour recompression distillation column}

Figure 1 shows a schematic illustration of the distillation column with direct vapour recompression heat pump. An ethanol-water solution in a feed storage tank (FST) at 


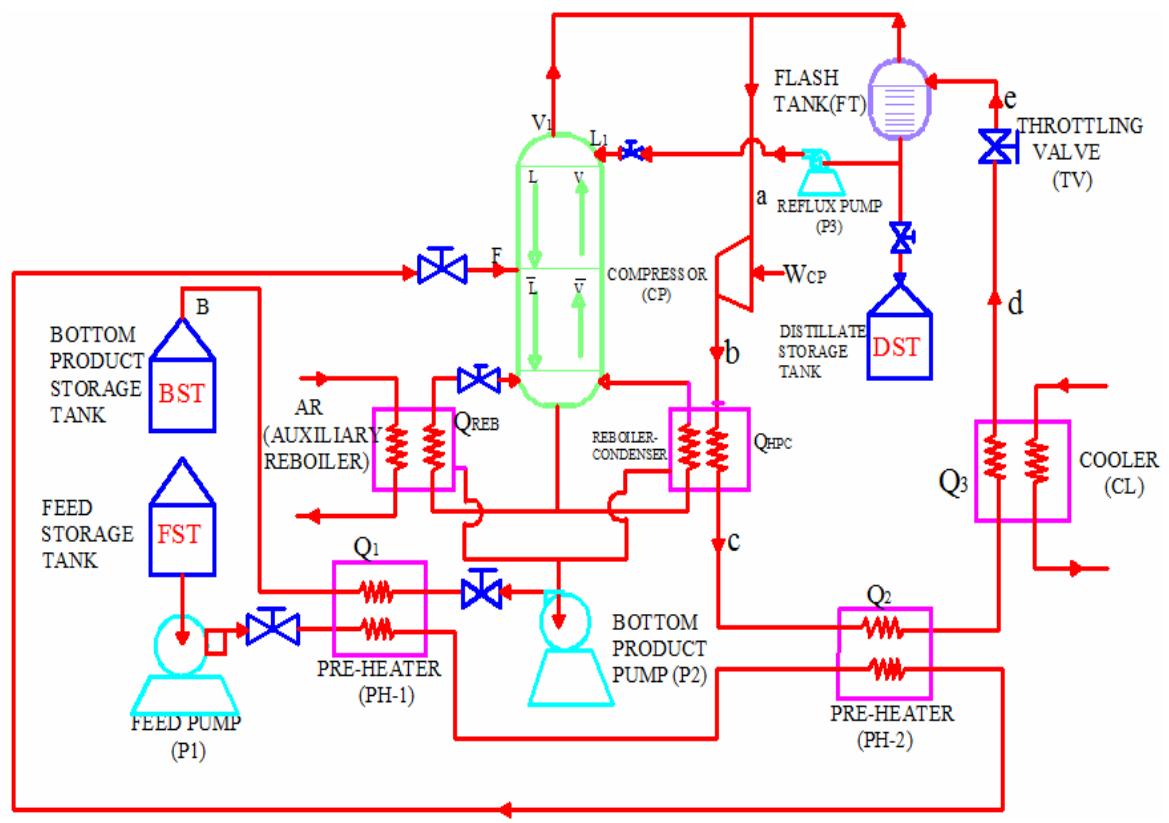

Fig. 1. Schematic Diagram of Column with Direct Vapour Recompression Heat Pump

ambient conditions, is preheated with bottom product and condensate in heat exchangers, preheaters PH1 and PH2, and fed to the column. An auxiliary reboiler (AR) is used to start the unit. This reboiler supplies the auxiliary heat duty, which is the heat of vaporization because the main reboiler can work only if there is some compressed vapour already available. The overhead vapours from the top are compressed in the compressor $(\mathrm{CP})$ up to the necessary pressure in such a way that its condensing temperature is greater than the boiling temperature of the column bottom product. The vapour is then condensed by exchanging heat within the tubes of the reboiler-condenser (RC). In a condenser, the inlet temperature is equal to the outlet temperature. Ethanol vapour will only lose its latent heat of condensation. At the same time, the cold fluid (ethanol-water mixture) in the reboiler will absorb this latent heat and its temperature will increase to boil up the mixture to temperature $\mathrm{T}_{\mathrm{CEV}}$. The liberated latent heat of condensation provides the boil-up rate to the column while the excess heat extracted from the condensate is exchanged with the feed in preheater PH2. The condensate, which is cooled in the cooler (CL) up to its bubble point at the column operating pressure, expands through the throttling valve (TV) at the same pressure and reaches the flash tank (FT). After expansion, the output phases are a vapour phase in equilibrium with a liquid phase. One part of the product in the liquid phase is removed as distillate and stored in the tank (DST), while the remainder is recycled into the column as reflux L1. The excess of vapour is recycled to the compressor.

\subsection{Methodology}

Like this work, nearly all publications in this field are based on modelling and simulation (Brousse et al., 1985; Ferre et al., 1985; Collura and Luyben, 1988; Muhrer et al, 1990; Oliveira 
et al. 2001). The mathematical modeling of the distillation system is derived by applying energy, composition and overall material balances together with vapour-liquid equilibrium under some assumptions (see Muhrer et al, 1990 and Enweremadu, 2007). These and other assumptions are aimed at simplifying the otherwise cumbersome heat-and mass-transfer, and the fluid flow equations Mori et al (2002).

\subsection{Calculation of the distillation column}

In this system, there is a direct coupling between the distillation column and the rest of the system, as the heat pump working fluid is the column's own fluid which, is a binary mixture of ethanol and water at composition $X_{D}$. Therefore, the set of equations are not solved separately as in distillation column assisted by an external heat pump.

The detailed calculation of the overall material and component material balance such as the bottom flow rate, $\mathrm{B}$ and distillate flow rate, $\mathrm{D}$; reflux ratio, $\mathrm{R}_{\mathrm{r}}$; the molar vapour flow rate which leaves the column top and feeds the condenser, $\mathrm{V}_{1}$; feed vapour flow rate, $\mathrm{V}_{\mathrm{F}}$; feed vapour fraction, q; vapour molar flow rate remaining at the bottom of the column, $\mathrm{L}_{2}$ are given (see Enweremadu, 2007).

The overall (global) energy balance equation applied to a control volume comprising the distillation column and the feed pre-heaters provides the total energy demand in the reboiler:

$$
\mathrm{Q}_{\mathrm{reb}}=\mathrm{Dh}_{\mathrm{D}}+\mathrm{Bh}_{\mathrm{B}}+\mathrm{L}_{1} \mathrm{~h}_{\mathrm{LV}, \mathrm{e}}+\mathrm{Q}_{\text {losses }}-\mathrm{Fh}_{\mathrm{F}}-\mathrm{Q}_{1}-\mathrm{Q}_{2}
$$

where $\mathrm{Q}_{\text {reb }}$ is the total heat load added to the reboiler, $\mathrm{Q}_{\text {losses }}$ represents the heat losses in the column, which are to be determined; $Q_{1}$ and $Q_{2}$ are the heat loads of the pre-heaters; $h_{L V, e}$ is latent heat of vaporisation downstream of throttling valve; $h_{D}$, is the enthalpy of the distillate; $h_{B}$ is the enthalpy of the bottom product; $h_{F}$, is the enthalpy of the feed. The details of the mass balance variables are determined in Enweremadu (2007).

The first step in the design of a distillation column is the determination of the number of theoretical plates required for the given separation. The theoretical trays are numbered from the top down, and subscripts generally indicate the tray from which a stream originates with $\mathrm{n}$ and $\mathrm{m}$ standing for rectifying and stripping sections respectively. The design procedure for a tray distillation column consists of determining the liquid and vapour composition or fraction from top to bottom, along the column. In calculating the composition profile of the column two equations relating liquid mole fraction to temperature and vapour mole fraction to the liquid fraction are used. The compositions at the top $\left(X_{D}\right)$ and bottom $\left(X_{B}\right)$ of the column are previously pre-established data. In this work, the minimum number of theoretical stages $\left(\mathrm{N}_{\mathrm{min}}\right)$ is calculated using Fenske's equation:

$$
N_{\min }=\frac{\log \left(\frac{X_{D}}{1-X_{D}} \cdot \frac{1-X_{B}}{X_{B}}\right)}{\log \alpha}
$$

where $\alpha$ is the relative volatility in the column. The actual number of plates is given by:

$$
N=\frac{N \min }{\eta_{T}}
$$


where $\eta_{T}$ is the tray efficiency.

\subsubsection{Heat losses from distillation column}

The heat loss from the distillation column is the main factor that affects heat added and removed at the reboiler and condenser respectively. Most distillation columns operate above ambient temperature, and heat losses along the column are inevitable since insulating materials have a finite thermal conductivity. Heat loss along the distillation column increase condensation and reduces evaporation. Thus, the amount of vapour diminishes in the upward part of the column, where the flow of liquid is also less than at the bottom.

To prevent loss of heat, the distillation column should be well insulated. Insulation of columns using vapour recompression varies with the situation. Where the column is hot and extra reboiler duty is used, the column should be insulated (Sloley, 2001). The imperfect insulation of the column causes some heat output.

In determining the heat loss from the distillation column, it is assumed that the temperature is uniform in the space between two plates. The heat transfer between the column wall and the surrounding is then determined from the well-known relationship for overall heat transfer coefficient:

$$
Q_{\text {Losses }}=U_{P} A_{\circ} \Delta T_{P}
$$

where $U_{p}$, the overall heat transfer coefficient is given by Gani, Ruiz and Cameron (1986), as

$$
U_{p}=f\left(h_{o}, h_{i}, K_{p}, A_{o}, A_{1}, A_{m}, t_{i n s}\right)
$$

where the temperature difference, $\Delta T_{p}$, is given as $\Delta T_{p}=T_{p}-T_{a m b}$

$h_{0}$, the heat transfer coefficient between the surroundings and the column external surface, is given as

$$
h_{\mathrm{o}}=\mathrm{f}\left(\mathrm{Nu}, K_{\mathrm{ins}}, \mathrm{d}_{\mathrm{o}}, \mathrm{t}_{\mathrm{ins}}\right)
$$

$\mathrm{h}_{\mathrm{i}}$ is the heat transfer coefficient inside the column; $K_{\mathrm{p}}$ is the thermal conductivity of the tray material; $A_{o}$ is the external area of heat exchange; $A_{i}$ is the internal area of heat exchange; $\mathrm{A}_{m}$ is the logarithmic mean area; $\mathrm{t}_{\mathrm{ins}}$ is the thickness of insulation.

The heat output is calculated with the general expression for convection around cylindrical objects.

$$
Q_{\text {loss }}=\frac{T_{P}-T_{\text {amb }}}{1 / h_{i} A_{i}+\frac{\ln \left(r_{\text {owall }} / r_{\text {ivall }}\right)}{K_{\text {wall }} \cdot A_{\text {wall }}}+\frac{\ln \left(r_{\text {ins }} / r_{\text {owall }}\right)}{K_{\text {ins }} \cdot A_{m}}+1 / h_{o} A_{o}}
$$

The column inner surface heat transfer resistance is neglected as the heat transfer coefficient for condensing vapor is large and therefore will have little effect on the overall heat transfer.

Based on the assumptions in Enweremadu (2007), the heat transfer due to free convection between the surroundings and the external column wall and due to conduction through the insulation materials is predicted. 
Also, from geometry of the insulated cylinder (Fig.2), the external diameter of insulation is given as

$$
\mathrm{d}_{\text {ins }}=\mathrm{d}_{\mathrm{o}}+2 \mathrm{t}_{\mathrm{ins}}
$$

Details of how the logarithmic mean diameter of the insulating layer $\left(\mathrm{d}_{\mathrm{ins}, \mathrm{m}}\right)$, external area of heat exchange $\left(A_{o}\right)$ and the logarithmic mean area $\left(A_{m}\right)$ can be found in Enweremadu (2007).

From dimensional analysis,

$$
h_{o}=\frac{K_{i n s} \cdot N u}{d_{o}+2 t_{i n s}}
$$

where, $t_{\text {ins }}$ is the thickness of insulation; $K_{\text {ins }}$ - thermal conductivity of the insulation materials; $\mathrm{Nu}$ - Nusselt number; $\mathrm{d}_{\mathrm{o}}$ - external diameter of column; $\mathrm{T}_{\mathrm{amb}}$ - temperature of the surrounding; $\mathrm{T}_{\mathrm{p}}$ - plate temperature.

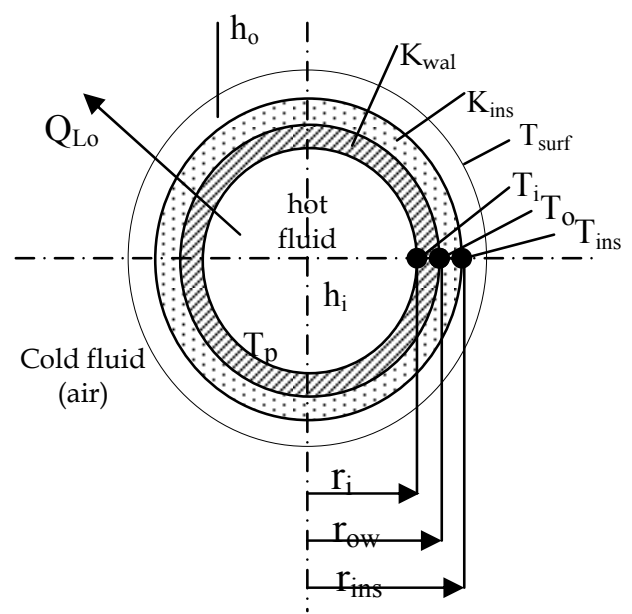

Fig. 2. Hypotethical Section of the Distillation Column with Insulation

For vertical cylinders, the commonly used correlations for free convection are adapted from Rajput (2002) as:

For laminar flow,

$$
\mathrm{Nu}=0.59(\mathrm{Gr} \cdot \mathrm{Pr})^{1 / 4} \text { for }\left(10^{4}<\mathrm{Gr} \cdot \operatorname{Pr}<10^{9}\right)
$$

For turbulent flow,

$$
N u=0.10(\mathrm{Gr} \cdot \operatorname{Pr})^{1 / 3} \text { for }\left(10^{9}<\mathrm{Gr} \cdot \operatorname{Pr}<10^{12}\right)
$$

where Gr is the Grashof number and Pr is Prandtl.

Based on the assumptions of neglecting $h_{i}, A_{i}$ and the effect of thermal resistance, equation (5) reduces to: 


$$
\mathrm{U}_{P}=\mathrm{f}\left(\mathrm{h}_{\mathrm{o}}, \mathrm{K}_{\mathrm{p}}, \mathrm{A}_{\mathrm{o}}, \mathrm{A}_{m}, \mathrm{t}_{\mathrm{ins}}\right)
$$

while equation (7) is given as

$$
Q_{\text {losses }}=\frac{\left(T_{p}-T_{\text {amb }}\right) \pi P_{s} N}{\frac{\ln \left(r_{\text {ins }} / r_{\text {ovall }}\right)}{K_{p} \cdot A_{m}}+\frac{1}{h_{o} A_{o}}}
$$

where $U_{P}=\frac{1}{\frac{\ln \left(r_{\text {ins }} / r_{\text {owall }}\right)}{K_{p} \cdot A_{m}}+\frac{1}{h_{o} A_{o}}}$

The heat loss from the column trays is given by

$$
Q_{\text {loss from trays }}=\frac{\left(T_{P}-T_{a m b}\right) 2 \pi P_{s} N}{\frac{\ln \left(r_{i n s} / r_{o}\right)}{K_{p} \cdot \frac{2 \pi P_{s} \cdot t_{i n s}}{\ln \left(1+\frac{2 t_{i n s}}{d_{o}}\right)}}+\frac{1}{\frac{K_{i n s} \cdot N u}{d_{o}+2 t_{i n s}} \cdot\left(\pi d_{i n s, m . P_{s}}\right)}}
$$

The total heat loss from the column is expressed as

$$
\text { Qloss }=\mathrm{Q}_{\text {loss from trays }}+\text { Heat loss from the two cylinder heads }
$$

Based on the assumptions made, heat loss through the cylinder heads is given by

$$
\text { Qloss at cylinder heads }=\frac{2\left(\mathrm{~T}_{\mathrm{p}}-\mathrm{Tamb}_{\mathrm{amb}}\right) \pi \mathrm{r}_{\mathrm{o}}^{2}}{\frac{\text { tins }}{\mathrm{K}_{\mathrm{p}}}+\frac{1}{h_{\mathrm{o}}}}
$$

Therefore,

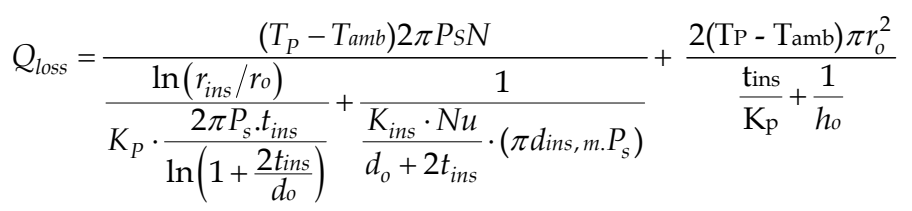

\subsection{Calculation of heat pump and compressor parameters}

The heat pump is thermodynamically linked to the column through the heat load from the pump to the column $\mathrm{Q}_{\mathrm{HPC}}$ and from the column to the pump $\mathrm{Q}_{\mathrm{CHP}}$, and reboiler-condenser temperature. These parameters provide the basis for the heat pump calculation.

The calculation of the heat pump parameters begins with the estimation of the working fluid condensation temperature obtained from the reboiler temperature and temperature drop across the heat exchangers.

$$
\mathrm{T}_{\mathrm{CHP}}=\mathrm{T}_{\mathrm{CEV}}+\Delta \mathrm{T}_{\mathrm{CHP}}
$$


where $\mathrm{T}_{\mathrm{CEV}}$ is the column vapourization (reboiler) temperature and $\Delta \mathrm{T}_{\mathrm{CHP}}$, a pre-established mean temperature difference across the heat exchangers (temperature drop in reboilercondenser). Next is the estimation of the relevant thermodynamic properties of the working fluid. These are obtained from thermodynamic correlations.

The thermodynamic properties are determined as functions of temperature. The relationships used for calculating the working fluid density, viscosity, thermal conductivity and heat capacity for input at various locations are presented in Enweremadu (2007). The condensation pressure, $\mathrm{P}_{\mathrm{CHP}}$ is expressed as a function of condensation temperature as

$$
\mathrm{P}_{\mathrm{CHP}}=\mathrm{f}\left(\mathrm{T}_{\mathrm{CHP}}\right)
$$

while the condensation pressure is determined from ideal gas equation.

The latent heat of condensation from column to heat pump is numerically exactly equal to the latent heat of vaporisation, but has the opposite sign: latent heat of vaporisation is always positive (heat is absorbed by the substance), whereas latent heat of condensation is always negative (heat is released by the substance). Latent heat of condensation is expressed as a function of condensation temperature and is determined from the relationship (Ackland, 1990):

$$
h_{L V, C H P}=\Delta H_{\text {vap }}\left[\frac{1-\frac{T_{C H P}}{T_{C}}}{1-\frac{T_{b p}}{T_{C}}}\right]\left[A+B\left(1-\frac{T_{C H P}}{T_{C}}\right)\right]
$$

where $\Delta \mathrm{H}_{\mathrm{vap}}$ is the heat of vapourisation at the boiling point of ethanol; $\mathrm{T}_{\mathrm{C}}$ is the critical temperature; $A$ and $B$ are constants.

The vapour specific volume at location "a" (entrance to the compressor) is expressed as a function of column condensation temperature, $\mathrm{T}_{\mathrm{CC}}$ and pressure at the top of the column, P TOP:

$$
v_{a}=\frac{\mathrm{T}_{\mathrm{cc}} x \mathrm{R}}{P_{\mathrm{TOP}}}
$$

Since compression is polytropic, at location " $b$ " (compressor discharge), the vapour specific volume is determined by:

$$
\mathrm{V}_{\mathrm{b}}=\boldsymbol{V}_{a}\left(\frac{P_{\text {TOP }}}{P_{\text {CHP }}+\Delta P}\right)^{\frac{1}{n}}
$$

where $\mathrm{n}$ is the polytropic index and $\Delta \mathrm{P}$ is the pressure increase across the compressor.

The vapour specific enthalpy at "a" is a function of top pressure, $\mathrm{P}_{\mathrm{TOP}}$ and top temperature, $\mathrm{T}_{\mathrm{TOP}}$.

$$
\mathrm{h}_{\mathrm{a}}=\mathrm{f}\left(\mathrm{T}_{\mathrm{TOP}}, \mathrm{P}_{\mathrm{TOP}}\right)
$$


The vapour specific enthalpy at " $b$ " may be determined as a function of compressor discharge temperature $\mathrm{T}_{\mathrm{b}}$ and condensation pressure $\mathrm{P}_{\mathrm{CHP}}$ but in this study, it is determined by the development of numerical computation with calculations utilizing the Redlich Kwong equation of state. The Redlich - Kwong equation of state is given as

$$
P=\frac{R T}{V-b}-\frac{a}{\left.T^{1 / 2} V(V+b)\right)}
$$

Where

$$
\begin{gathered}
\mathrm{a}=0.42747\left(\frac{R^{2} T_{c}^{5 / 2}}{P_{c}}\right) \\
\mathrm{b}=0.08664\left(\frac{R T_{c}}{P_{c}}\right)
\end{gathered}
$$

and $\mathrm{P}=$ pressure (atm); $\mathrm{V}=$ molar volume (liters $/ \mathrm{g}$-mol); $\mathrm{T}=$ temperature $(\mathrm{K}) ; \mathrm{R}=$ gas constant (atm. Liter/g-mol.K); $\mathrm{P}_{\mathrm{c}}=$ critical pressure (atm).

Taking the reference state for the enthalpy of liquid ethanol $h_{L}^{o}$, temperature, $\mathrm{T}_{\mathrm{o}}$ and the enthalpy of vaporisation $\Delta H_{v a p}^{o}$, then the enthalpy of ethanol vapour as an ideal gas at temperature $\mathrm{T}$ can be calculated from

$$
\mathrm{h}_{\mathrm{b}}^{\mathrm{o}}={ }_{\mathrm{h}}^{\mathrm{o}}+\Delta H_{\text {vap }}^{o}+\int_{T_{o}}^{T} C_{p}^{o} d T
$$

Using the isothermal enthalpy departure and the Redlich-Kwong equation of state, the enthalpy of ethanol vapour at $\mathrm{T}$ and $\mathrm{P}$ can be calculated from

$$
h b=h_{L}^{o}+\Delta H_{\text {vap }}^{o}+\int_{T_{o}}^{T} C_{p}^{o} d T+R T\left[Z-1-\frac{1.5 a}{b R T^{1.5}} \ln \left(1+\frac{b}{V}\right)\right]
$$

where $\mathrm{Z}$ is the compressibility factor, $\mathrm{Cp}$ is the molar specific heat capacities of gases at zero pressure given as a polynomial in temperature.

Equations 24-26 are then solved with POLYMATH(R) Simultaneous Algebraic Equation Solver (See Enweremadu, 2007).

The vapour specific heat at location " $\mathrm{e}$ " is calculated thus (Oliveira et al, 2002):

$$
h_{e}=h_{L, c}-C p_{L} \Delta T S C
$$

The specific liquid enthalpies have been assumed to be simple functions of temperature.

The liquid specific enthalpy at location " $c$ " is determined from EZChemDB Thermodynamic Properties Table for Ethanol (AM Cola LLC, 2005) using the expression

$$
h \mathrm{~L}, \mathrm{c}=\mathrm{f}(\mathrm{TCHP})
$$


while the liquid specific enthalpy at location e (at the exit of the throttling valve) is determined from

$$
\mathrm{h}_{\mathrm{L}, \mathrm{e}}=\mathrm{f}\left(\mathrm{T}_{\mathrm{CC}}\right)
$$

The temperature at compressor discharge is determined from the knowledge of the compressor efficiency. The ideal discharge temperature (the temperature that gives an overall change in entropy equal to zero) is calculated before correcting with the compressor efficiency.

$$
\mathrm{T}_{\mathrm{b}}=\mathrm{T}_{\mathrm{TOP}}+\frac{\mathrm{T}_{\mathrm{TOP}}\left[-1+\left(\frac{\mathrm{P}_{\text {СHP }}+\Delta \mathrm{P}}{\mathrm{P}_{\mathrm{TOP}}}\right)^{0.263}\right]}{\eta_{\text {pol }}}
$$

The dryness fraction after the isenthalpic expansion is given by

$$
\beta_{e}=\frac{h_{e}-h_{L, e}}{h_{L V, e}}
$$

where the molar latent heat of vaporization at location " $\mathrm{e}$ " is adapted from Ackland (1990):

$$
h_{L V, e}=\Delta H_{\text {vap }_{b p}} *\left(\left(1-T_{d} / T_{C}\right) /\left(1-T_{b p} / T_{C}\right)\right)^{\wedge} A+B\left(\left(1-T_{d} / T_{C}\right)\right)
$$

Since this is a throttling process, $T_{d}=T_{e}$ and $h_{d}=h_{e}$

The molar vapour flow rate which is recycled in the flash tank and conveyed to the compressor is calculated by

$$
V_{R}=\frac{V_{1} \beta_{e}}{1-\beta_{e}}
$$

Therefore, the molar flow rate across the compressor is expressed as

$$
\dot{M}=V_{1}+V_{R}
$$

While the dryness fraction at condenser exit is determined by

$$
\beta_{c}=\frac{Q_{23} / \dot{M}-C_{P_{L}}\left(T_{C H P}-T_{d}\right)}{h_{L V, C H P}}
$$

where $Q_{23}$ is the distribution of excess heat between the pre-heater $Q_{2}$ and the cooler $Q_{3}$ and $C \mathrm{p}_{\mathrm{L}}$ is the molar specific heat of the working fluid in the liquid phase.

The energy balance, applied to the heat pump working fluid, yields the available energy for exchange at the condenser, as follows:

$$
Q_{c d}=\dot{M}\left[C p_{v}\left(T_{b}-T_{C H P}\right)+\left(1-\beta_{c}\right) h_{L V, C H P}\right]
$$


A comparison is made between this energy available at the condenser, $Q_{c d}$, with the energy required by the column reboiler, $Q_{\text {reb. }}$ This brings about the following heat load control.

i. If the rate of energy available at the heat pump condenser, $Q_{c d}$, is greater than the rate of energy required by the reboiler $Q_{\text {reb}}$, then the condenser gives up $Q_{\text {reb }}$ to the reboiler and the remaining energy is conveyed to the preheaters $\left(Q_{2}\right)$ and cooler $\left(Q_{3}\right)$

$$
\text { if } Q_{c d}>Q_{r e b} \text { then } Q_{H P C}=Q_{r e b}
$$

ii. But if $Q_{c d}$ is smaller than or equal to $Q_{r e b}$, then all energy available is transferred to the reboiler and the auxiliary reboiler will provide the "extra" $Q_{\text {reb }}$ i.e.

$$
\text { if } Q_{c d} \leq Q_{r e b} \text { then } Q_{H P C}=Q_{c d}
$$

where $\mathrm{Q}_{\mathrm{HPC}}$ is the energy yield by the heat pump to the distillation column. The factor by which the heat pump contributes to the heat load of the reboiler is given as

$$
f=\frac{Q_{H P C}}{Q_{r e b}}
$$

For a distillation column with vapour recompression, driving the compressor uses the most energy. Thus, the power consumption must be known so as to assess the feasibility of such a system. For a perfect gas, that is, a gas having a constant specific heat, $\mathrm{Cp}=\mathrm{Cp}^{\circ}$, then the specific enthalpy rise between the compressor inlet and outlet is

$$
\Delta h=h_{b}-h_{a}=C_{p}^{o}\left(T_{b}-T_{a}\right)
$$

And if the change of state is isentropic,

$$
\Delta h=\int_{a}^{b} v d p=\frac{\gamma}{\gamma-1} \cdot \frac{R u \cdot T}{\dot{M}}\left[\left(\frac{P_{b}}{P_{a}}\right)^{\frac{\gamma-1}{\gamma}}-1\right]
$$

In reality, ideal gases do not exist and therefore improvements are made on equation (41).

Therefore, compression is polytropic and the isentropic index $\gamma$, is replaced by the polytropic index, $\mathrm{n}$ (see Enweremadu, 2007). The compressor polytropic efficiency $\eta_{\text {pol }}=0.7-0.8$ is used.

Also, because a saturated vapour, especially at higher pressures, shows deviations from the ideal gas behaviour, the compressibility factor, $\mathrm{Z}$ is used. Hence equation (41) becomes

$$
\Delta h_{\text {eff }}=\frac{n}{n-1} \cdot \frac{Z \cdot R_{u} \cdot T_{a}}{\eta_{p o l} \cdot \dot{M}}\left[\left(\frac{P_{b}}{P_{a}}\right)^{\frac{n-1}{n}}-1\right]
$$

Therefore, the power input for driving the compressor is the energy that increase the enthalpy of the gas 


$$
\dot{W}_{c p}=\frac{\dot{M}}{\eta_{p o l}} \frac{n}{n-1} P_{a} v_{a}\left[\left(\frac{P_{b}}{P_{a}}\right)^{\frac{n}{n-1}}-1\right]
$$

Equation (43) shows that the pressure ratio $\frac{P_{b}}{P_{a}}$ is crucial to the power requirement. This ratio or the pressure increase to be provided by the compressor of a column with vapour recompression is influenced by the following (Meili, 1990; Han et al, 2003):

- Pressure drop in vapour ducts (pipes) and over valves and fittings, $\Delta \mathrm{P}_{p}$.

- Pressure drop across the column, $\Delta \mathrm{P}_{c l}$.

- The difference in boiling points between the top and bottom products, $\Delta \mathrm{P}_{b}$.

- Temperature difference in the reboiler, $\Delta \mathrm{P}_{\mathrm{CHP}}$.

\subsubsection{Determination of the pressure increase over the compressor}

Pressure drops in the vapour ducts may be caused by frictional loss, $\Delta \mathrm{P}_{\mathrm{f}}$; static pressure difference, due to the density and elevation of the fluid, $\Delta \mathrm{P}_{\mathrm{s}}$; and changes in the kinetic energy, $\Delta \mathrm{P}_{\mathrm{k}}$. Since, there are elbows, valves and other fittings along the pipes then the pressure drop is calculated with resistance coefficients specifically for the elements. Therefore, the pressure drop along a circular pipe with valves and fittings is given by

$$
\Delta P_{P}=\Delta P_{s}+\Delta P_{f}+\Delta P_{K}=\frac{\rho u^{2}}{2}\left(1+\frac{\lambda l_{p}}{d_{P}}+\sum \xi\right)
$$

and $\mathrm{u}$ is the fluid velocity; $d_{p}$ is the pipe diameter and $\rho$ is the fluid density; $\lambda$ is the Fanning friction factor which is a function of Reynolds number; $l_{p}$ is the pipe length; $\mu$ is the dynamic viscosity of the fluid and $\xi$ is the resistance coefficient.

The pressure drop over the entire distillation column, $\Delta \mathrm{P}_{\mathrm{cl}}$ is caused by losses due to vapour flowing through the connecting pipes and through pressure drop over the stages in rectifying and stripping section. This depends mainly on the column internals, number of stages, gas load and operating conditions. $\Delta \mathrm{P}_{\mathrm{cl}}=0$, if zero vapour boil up is assumed. But constant pressure drop is assumed in this work. The pressure drop over a stage consists of dry and wet pressure drop. The dry pressure is caused by vapour passing through the perforation of the sieve tray. The aerated liquid (static head) on the tray causes the wet pressure drop. Constant pressure drop per tray have been estimated from several authors to be equal to $5.3 \mathrm{mmHg}$ per tray (Muhrer, Collura and Luyben 1990). The total column pressure drop has been found by summing plate pressure drops $\Delta \mathrm{P}_{\mathrm{cl}}$

$$
\Delta P_{c l}=0.13332 x 5.3 \times N=0.707 N
$$

The top and bottom products have different compositions and boiling points. For a fixed bottom temperature of the column, there is a vapour - pressure difference, $\Delta \mathrm{P}_{\mathrm{b}}$ due to the difference in boiling points.

$$
\Delta \mathrm{Pb}=P_{\text {TоР }}-P_{\text {воттом }}
$$


where,

$$
\begin{aligned}
& \mathrm{P}_{\text {тоР }}=10\left[\text { А }^{\text {тор- }} \frac{\mathrm{B}_{\text {TоР }}}{\mathrm{T}_{\text {TOP }}+\mathrm{C}_{\mathrm{TOP}}}\right]
\end{aligned}
$$

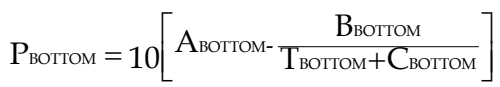

The temperature difference in the reboiler-condenser is expressed by means of the vapour pressure equation as a pressure difference, $\Delta \mathrm{P}_{\mathrm{CHP}}$. Temperature differences of $8-17 \mathrm{o} C$ are quite common for ethanol-water distillation (Gopichand et al, 1988; Canales and Marquez, 1992). Using the Clausius - Clapeyron equation for a two- point fit,

$$
\Delta P_{C H P}=\mathrm{e}^{-\frac{\Delta H v a p}{\mathrm{R}}}\left(\frac{-\Delta T_{C H P}}{T_{C H P . T C E V}}\right)
$$

Therefore the total pressure increase over the compressor becomes

$$
\Delta \mathrm{P}=\Delta \mathrm{Pb}+\Delta \mathrm{P}_{\mathrm{cl}}+\Delta \mathrm{PCHP}+\Delta \mathrm{P}_{\mathrm{p}}
$$

For this distillation system, the compression (pressure) ratio is

$$
\frac{P_{b}}{P_{a}}=\frac{P_{\mathrm{CHP}}+\Delta P}{P_{\text {TOP }}}
$$

where $\mathrm{P}_{\mathrm{TOP}}$ is inlet pressure (vapour pressure at top temperature).

Other compressor parameters are calculated by the following equations:

i. Compressor power input is determined from equation (43) and (51)

$$
\dot{W}_{c p}=\frac{\dot{M}}{\eta_{p o l}} \frac{n}{n-1} P_{\text {TOP }} \cdot v_{a}\left[\left(\frac{P_{\text {СHP }}+\Delta P}{P_{\text {TOP }}}\right)^{\frac{n-1}{n}}-1\right]
$$

ii. Compressor heat load rate (energy balance)

$$
Q_{c p}=\eta_{p o l} \dot{W}_{c p}-\dot{M}\left(h_{b}-h_{a}\right)
$$

iii. Compressor volumetric efficiency

$$
\eta_{v}=C_{v}\left\{1-r\left[\left(\frac{P_{\mathrm{CHP}}+\Delta P}{P_{\mathrm{TOP}}}\right)^{\frac{1}{m}}-1\right]\right\}
$$

where $\mathrm{Cv}$ is empirical volumetric coefficient and $\mathrm{r}$ is the compressor clearance ratio.

iv. Compressor nominal capacity or compressor displacement rate

$$
V_{c} \omega=\frac{\dot{M} v_{a}}{\eta_{v}}
$$


where $V_{c}$ is compressor displacement volume $\left(\mathrm{m}^{3}\right)$ and $\omega$ is angular velocity $\left(\mathrm{rad} \mathrm{s}^{-1}\right)$.

\subsubsection{Determination of the reboiler-condenser parameters}

The overall heat transfer coefficient between condenser and reboiler is given by

$$
(U A)_{H P C}=\frac{Q_{H P C}}{\Delta T_{C H P}}
$$

However, a careful analysis reveals that the overall heat transfer coefficient $U$ is an explicit function of Prandtl, Reynolds and Nusselt numbers, and depends on other properties such as viscosity and thermal conductivity. The overall heat transfer coefficient referenced to inner surface is given by

$$
\frac{1}{\mathrm{U}}=\frac{1}{h_{i}}+\left(r_{i} / r_{0}\right) \frac{1}{h_{0}}+\frac{r_{i} \ln \left(r_{o} / r_{i}\right)}{2 K_{\text {wall }}}
$$

As thermal resistance of the wall is negligible, $\left(\mathrm{K}_{\text {wall }}\right.$ is large and $\left.\ln \left(\mathrm{r}_{\mathrm{o}} / \mathrm{r}_{\mathrm{i}}\right)\right) \approx 0$, it is then compared with the inner tube diameter $\left(r_{i} / r_{o} \approx 1\right)$

Then

$$
\begin{gathered}
\frac{1}{U}=\frac{1}{h_{i_{e x}}}+\frac{1}{h_{e x}} \\
h_{e x}=\frac{0.023 K m}{d_{o_{e x}}}(\operatorname{Re} m)^{0.8}(\operatorname{Pr} m)^{0.4}\left(\frac{\mu \text { wall }}{\mu m}\right)^{0.14}
\end{gathered}
$$

where $\mu_{m}$ is the mean bulk fluid viscosity and $\mu_{\mathrm{w} \text { all }}$ is the viscosity of the liquid at the wall.

The expression for condensation at low velocities inside tubes is adapted from (Holman, 2005).

$$
h_{i_{e x}}=0.555\left[\frac{\rho_{l}\left(\rho_{l}-\rho_{v}\right) K L^{3} g h_{f g}^{\prime}}{\mu L d_{i_{e x}}\left(T_{c H P}-T_{\text {wall }}\right)}\right]^{0.25}
$$

where $h_{\mathrm{fg}}^{\prime}=\mathrm{h}_{\mathrm{fg}}+0.375 \mathrm{C}_{\mathrm{p}_{\mathrm{L}}}\left(\mathrm{T}_{\mathrm{CHP}}-\mathrm{T}_{\text {wall }}\right)$

where $\mathrm{K}_{\mathrm{L}}$ is thermal conductivity of the liquid, $\mathrm{di}_{\mathrm{ex}}$ is the inside diameter of the reboilercondenser tubes and $\mu_{\mathrm{L}}$ is the density of the condensate (liquid).

Therefore, the overall heat transfer coefficient may be determined from

$$
\frac{1}{U A_{H P C}}=\frac{1}{\frac{0.023 K_{m}}{d_{o_{e x}}}\left(\frac{\rho_{m} u d_{e x}}{\mu_{m}}\right)^{0.8}\left(\frac{C_{p m}}{K_{m}}\right)^{0.4}\left(\frac{\mu_{\text {wall }}}{\mu_{m}}\right)^{0.14}}+\frac{1}{0.555\left[\frac{\rho_{L}\left(\rho_{L}-\rho_{v}\right) K_{L}^{3} g h_{f 8}^{\prime}}{\mu_{L} d_{i_{e x}}\left(T_{C H P}-T_{\text {wvall }}\right)}\right]}
$$

Assuming adiabatic expansion at the throttling valve, then 


$$
\mathrm{h}_{\mathrm{e}}=\mathrm{h}_{\mathrm{d}}=\mathrm{h}_{\mathrm{L}, \mathrm{c}}-\mathrm{Cp}_{\mathrm{L}} \cdot \Delta \mathrm{T}_{\mathrm{SC}}
$$

From the condenser prescribed degree of sub-cooling, the temperature of the working fluid after cooling and before throttling is given by

$$
\mathrm{T}_{\mathrm{d}}=\mathrm{T}_{\mathrm{CHP}}-\Delta \mathrm{T}_{\mathrm{SC}}
$$

where $\Delta \mathrm{T}_{\mathrm{SC}}$ is the degree of sub-cooling $(\mathrm{K})$

The corresponding latent heat (enthalpy) is given as

$$
h_{d}=h_{L, c}-C_{P_{L}} \Delta T_{S C}
$$

\subsection{Analysis of distribution of excess heat rate}

The distillation system uses the column's working fluid as refrigerant and does not execute a closed cycle. Therefore the excess heat which may occur is not assessed by an overall energy balance but by the method of Oliveira et al (2001). When the energy available at the condenser $\mathrm{Q}_{\mathrm{cd}}$, is greater than the energy required by the reboiler $\mathrm{Q}_{\mathrm{reb}}$, the column receives the amount $Q_{c d}$ and the energy left over corresponds to the excess. But if $Q_{c d}$ is smaller than or equal to $Q_{r e b}$, then all the energy available is transferred to the reboiler, i.e. there will be no excess. Thus,

$$
\begin{gathered}
\text { if } Q_{c d}>Q_{r e b} \text { then } Q_{23}=Q_{c d}-Q_{r e b} \\
\text { if } Q_{c d} \leq Q_{r e b} \text { then } Q_{23}=0
\end{gathered}
$$

where $\mathrm{Q}_{23}$ is the excess heat due to energy interactions between the heat pump and the reboiler.

The distribution of the excess heat rate, $\mathrm{Q}_{23}$, between the pre-heater $\left(\mathrm{Q}_{2}\right)$ and cooler $\left(\mathrm{Q}_{3}\right)$ is accomplished by controlling the feed condition pre-heated by $\mathrm{Q}_{2}$. In other words, the value of $\mathrm{Q}_{2}$ should be such that the feed reaches a prescribed condition. The pre-heating of the feed is carried out by $Q_{1}$ (heat exchanged between the bottom product and the feed) and $Q_{2}$ (heat exchange between the heat pump working fluid and the feed), in the heat exchangers. The heat provided by the bottom product is determined as follows:

$$
Q_{1}=B \cdot C_{p_{B}}\left(T_{C E V}-T_{B E}\right)
$$

where, $\mathrm{T}_{\mathrm{CEV}}$ is the column evaporation temperature. $\mathrm{C}_{\mathrm{B}}$ is the specific heat of the bottom product. $\mathrm{T}_{\mathrm{BE}}$ is the temperature at the bottom product flow exit.

The best feed condition is that of saturated liquid (Halvorsen, 2001). The energy required to pre-heat the feed to reach saturated condition is expressed as

$$
Q_{F S L}=F \cdot C_{P F}\left(T_{S a t, F}-T_{F}\right)
$$

where, $T_{s a t}{ }_{F}$ and $T_{F}$ are the saturation temperature of the feed source and the temperature of the feed source respectively. $\mathrm{Cp}_{\mathrm{F}}$ is the specific heat of the feed source.

To make the feed a saturated vapour, the energy required is given as 


$$
\mathrm{Q}_{\mathrm{FSV}}=\mathrm{Q}_{\mathrm{FSL}}+F h_{L V, F}
$$

It is important to verify whether $\mathrm{Q}_{1}$ alone is capable of pre-heating the feed to reach the desired condition, otherwise the amount of heat that should be withdrawn from the second pre-heater $\mathrm{Q}_{2}$, will be determined as

$$
Q_{\text {withdrawn }}=F \cdot C_{p_{F}}\left(T_{s a t, F}-T_{F}\right)+0.5 F h_{L V, F}
$$

The value of heat at the second pre-heater $\mathrm{Q}_{2}$ should be, at the most equal to $\mathrm{Q}_{\text {withdrawn }}$ to prevent the feed reaching $50 \%$ dry. Therefore, a convenient heat load control could be made as follows:

$$
\begin{aligned}
& \text { If } \mathrm{Q}_{23}>\mathrm{Q}_{\text {withdrawn, then } \mathrm{Q}_{2}=\mathrm{Q}_{\text {withdrawn }}} \mathrm{Q}_{3}=\mathrm{Q}_{23}-\mathrm{Q}_{2} \\
& \text { If } \mathrm{Q}_{23}<\mathrm{Q}_{\text {withdrawn, }} \text { then } \mathrm{Q}_{2}=\mathrm{Q}_{23,} \quad \mathrm{Q}_{3}=0
\end{aligned}
$$

\subsection{Thermodynamic analysis}

Since vapour recompression uses a refrigeration cycle rather than a Carnot cycle, the performance of the heat pump is defined according to the following relation;

$$
C O P_{h}=\frac{Q_{H P C}+Q_{23}}{\dot{W}_{c p}}
$$

The thermodynamic efficiency of a separation process is the ratio of the minimum amount of thermodynamic work required for separation to the minimum energy required for the separation (Olujic et al, 2003). For a vapour recompression distillation column, the energy required for separation process is composed of the reboiler heat load, $\mathrm{Q}_{\mathrm{reb}}$, and the compressor power input, $\dot{\mathrm{W}}_{\mathrm{cp}}$

$$
\mathrm{Q}_{\mathrm{T}}=Q_{r e b}+\dot{\mathrm{W}}_{c p}
$$

For the separation of a binary mixture by distillation the minimum thermodynamic energy required to achieve complete separation is given by (Liu and Quian, 2000):

$$
W_{\text {min }}=-R T_{T O P}\left(X_{F} \ln \left(X_{F}\right)+\left(1-X_{F}\right) \ln \left(1-X_{F}\right)\right)
$$

Then the thermodynamic efficiency is expressed as:

$$
\eta_{V R C}=\frac{\mathrm{W}_{\min }}{\mathrm{Q}_{\mathrm{T}}}
$$

\subsection{Solution method and error analysis}

The equations that model the system components were grouped together in one single system. The analyses of the status of the variables were carried out to identify those that were the input data and those which were the unknowns. The equations were then grouped 
together, resulting in a set of non-linear algebraic equations, which were solved iteratively based on the step by step use of the successive substitution method. Solution was obtained when convergence was attained. The convergence was checked by using the criterion:

$$
\varepsilon_{\mathrm{a}}=\frac{\mathrm{X}_{\mathrm{i}+1}-\mathrm{X}_{\mathrm{i}}}{\mathrm{X}_{\mathrm{i}+1}} \times 100 \%
$$

The model is coded in MATLAB environment and used to evaluate the unknowns. A control programme for column VRC was written to compare the actual column (column in which the parameters studied were considered, $\mathrm{VRC}_{\Delta \mathrm{P}) \text {. }}$

\section{Discussion of results}

\subsection{Effects of pressure increase over the compressor}

Figure 3 shows how the compressor power input, $\dot{W}_{c p}$ varies with the pressure increase over the compressor, $\Delta \mathrm{P}$. It is obvious from the plots that an increase in pressure over the compressor increases the compression (pressure) ratio leading to increase in compressor power input. The curve in Figure 3 shows the effect of pressure increase over the compressor on coefficient of performance. As the pressure increase over the compressor, $\Delta \mathrm{P}$ increases, the compression ratio increases and the coefficient of performance, COP decreases due to increase in compressor power input.

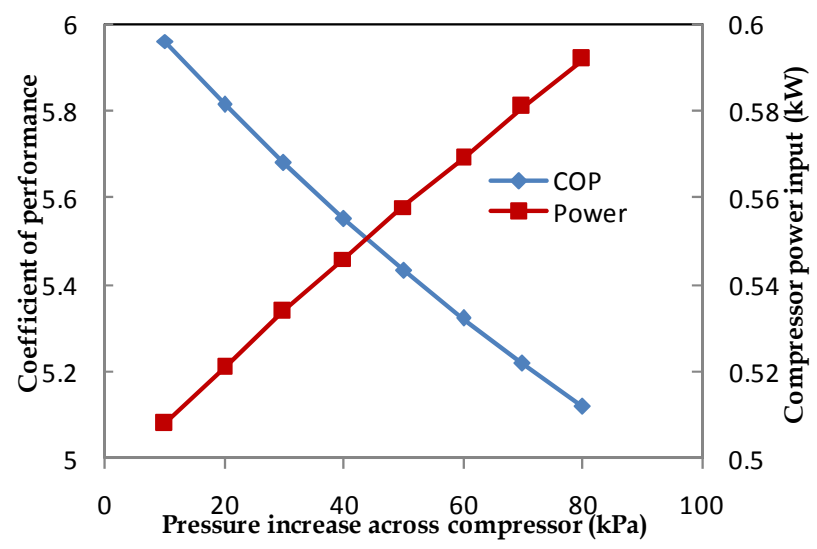

Fig. 3. The variation of coefficient of performance and compressor power input with pressure increase across compressor

In Figure 4, a negative non-linear relationship exists between the compressor volumetric efficiency and pressure increase over the compressor. For a given compressor nominal capacity, when the pressure increase across the compressor, $\Delta \mathrm{P}$ increases, the pressure ratio also increases resulting in the reduction in volumetric efficiency.

The influence of pressure increase over the compressor, $\Delta \mathrm{P}$ on the required compressor displacement rate $(\mathrm{Vc} \omega)$ is shown in Figure 4. The linear relationship that exists between the 


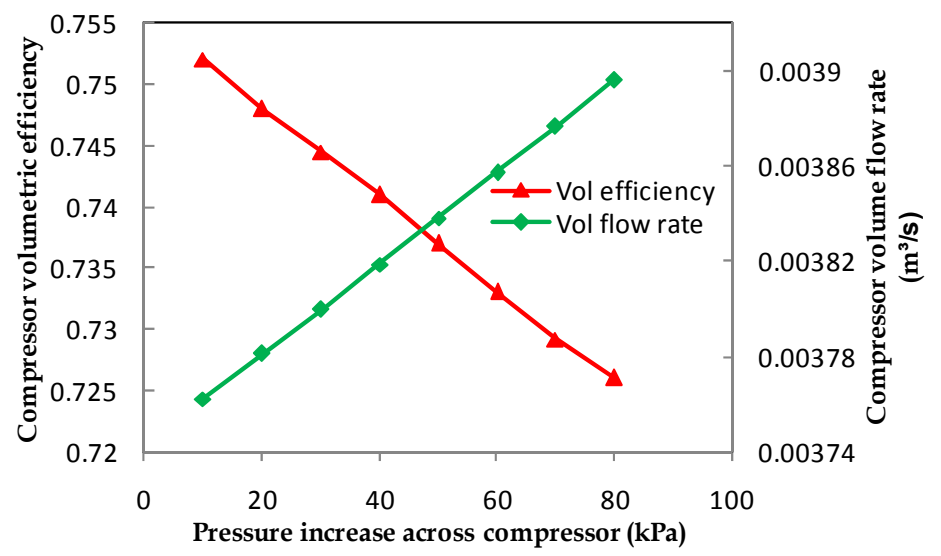

Fig. 4. The variation of compressor volumetric efficiency and volume flow rate with pressure increase across compressor

variables indicates that the compressor displacement rate is directly proportional to $\Delta \mathrm{P}$. $\mathrm{A}$ reduction in compressor volumetric efficiency caused by increase in $\Delta \mathrm{P}$, increases the compressor displacement rate. This implies an increase in the displacement volume required although this cannot be observed in the figures. The compressor displacement required for a given speed is related to compressor size. For the large specific volume obtained, $9.74 \mathrm{~m}^{3} \mathrm{~kg}^{-1}$ ethanol as the heat pump working fluid will require a compressor of greater capacity i.e large displacement rate.

It can be observed from Figure 5 that an increase in pressure increase across the compressor, $\Delta \mathrm{P}$ increases the total energy consumption.

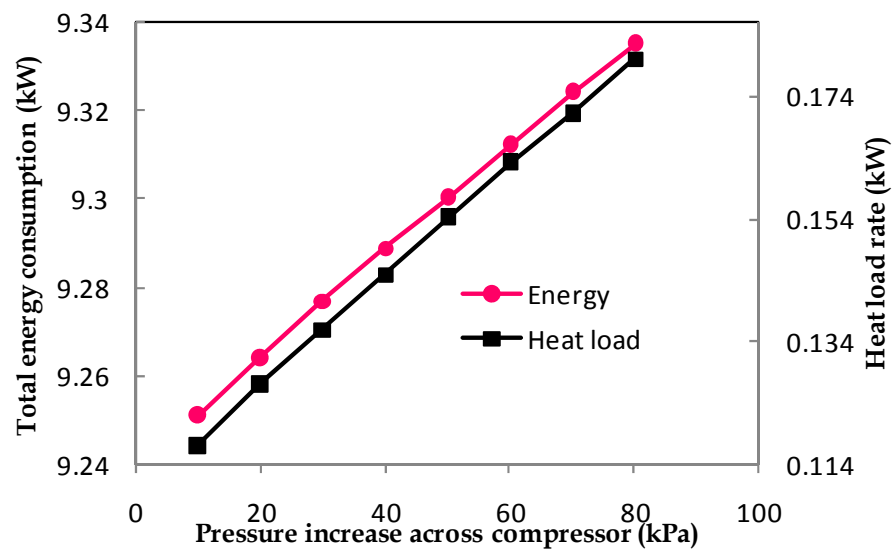

Fig. 5. The variation of total energy consumption and heat load rate with pressure increase across compressor

For a given reboiler heat transfer rate, $\mathrm{Q}_{\mathrm{reb}}$, it is obvious that as $\Delta \mathrm{P}$ increases, the total energy consumption increases. The total energy consumption and hence the energy 
savings from the work of Oliveira et al (2001) in heat pump distillation gave lower values. This could be attributed to non-consideration of the effect of pressure increase over the compressor and the subsequent increase in compression ratio and in compression power input respectively.

\subsection{Effects of column heat loss}

The direct effect of column heat loss could be seen from equation (17). From the equation, it follows that, for a given reboiler heat load or heat expenditure, fewer trays are required for a given separation if heat losses are reduced. Where heat loss occurs, more vapour has to be produced in the reboiler, since the reboiler must provide not only the heat removed in the condenser but also the heat loss. The effect of this is a decrease in process and energy efficiency. Indirectly, heat loss affects the column size in terms of number of plates. In the control system, the reflux ratio was as high as 7.5 compared with 5.033 obtained for the actual system. Therefore, if heat losses are properly accounted for, there may not be any need for downward review of the number of plates in order to reduce the reflux ratio (Enweremadu and Rutto, 2010). Therefore, pressure drop across the column, $\Delta \mathrm{P}_{\mathrm{cl}}$ and the difference in boiling points between the top and bottom products, $\Delta \mathrm{P}_{\mathrm{b}}$ which have the most profound effects on the pressure increase across the compressor, $\Delta \mathrm{P}$ will be properly predicted. The overall implication of this is that the column size would be determined properly.

\subsubsection{Overall heat transfer coefficient}

Analysis of the overall heat transfer coefficient, $U$ of the heat pump reboiler-condenser revealed an increase in the value of $U$. This was expected as the value of $U$ in boiling and condensation processes are high. Also, the value of the heat transfer coefficient of the condensing ethanol is dominated the relationship used in determining $\mathrm{U}$. A low value of overall heat transfer coefficient $U$ will result in an increase in the heat exchanger surface area which may be a disadvantage to ethanol-water system. But the results from this work showed an increase in the value of $U$ with the implication of a reduction in the reboilercondenser heat transfer area.

The variation of the reboiler-condenser thermal conductance (UA) with the heat pump distribution factor, $\mathrm{f}$, is shown in Figure 6. The plots show that the greater the heat load taken by the heat pump i.e. larger f's, the larger the thermal conductance, UA, and the larger the heat exchanger area. However, for better performance of any heat transfer system, the thermal resistance $\left(R_{\text {th }}\right)$ which is the inverse of thermal conductance $\left(R_{t h}=1 / U A\right)$, should be as low as possible. Therefore the value of the heat transfer area for the $\mathrm{VRC}_{\Delta \mathrm{P}}$ system will be smaller compared to the VRC system. Hence, the reboiler-condenser studied has a better performance.

The relationship between the thermal conductance, UA and the reboiler-condenser temperature difference, $\Delta \mathrm{T}_{\mathrm{CHP}}$ shows that the higher the reboiler-condenser temperature difference, the lower the thermal conductance. The implication of this is that a higher $\Delta \mathrm{T}_{\mathrm{CHP}}$ causes a reduction of the necessary heat transfer area. However, beyond a certain limit of the thermal driving force, the heat transfer area and the performance of the heat pump reboiler-condenser reduces. This is expected as higher $\Delta \mathrm{T}_{\mathrm{CHP}}$ leads to higher compression ratio, higher compressor power input and higher energy consumption. 


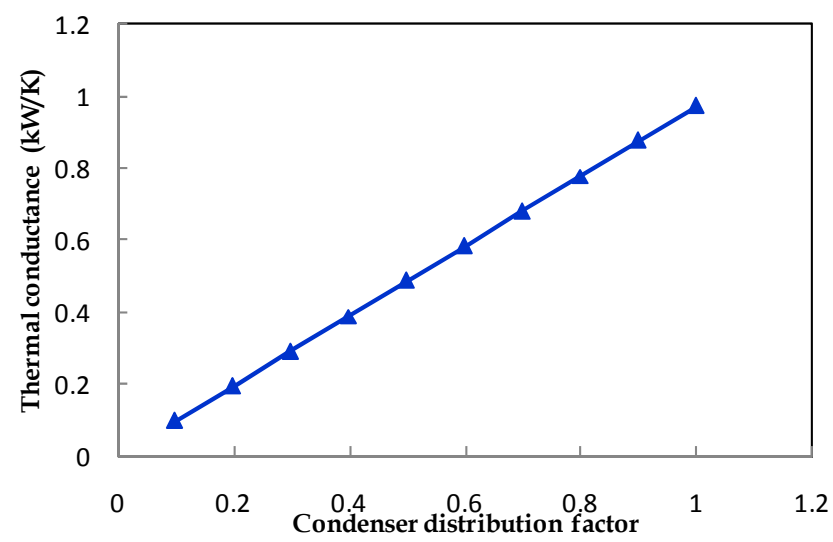

Fig. 6. Variation of Reboiler-condenser thermal conductance with condenser distribution factor

\subsection{Comparison of the vapour recompression distillation systems}

Table 1 summarises the comparison of some parameters of the two vapour recompression columns studied, the control (VRC) and the actual $\left(\mathrm{VRC}_{\Delta \mathrm{P}}\right)$. Both systems operate at 101.2 $\mathrm{kPa}$ and the effect of pressure drop effect is considered to account properly for variations in heat duty. A pressure drop of $0.707 \mathrm{kPa}$ per tray is assumed here as a reasonable estimate for the purposes of this study. The pressure ratio as used throughout this work is the ratio of the condensation pressure, $\mathrm{P}_{\mathrm{CHP}}$ to the top pressure, $\mathrm{P}_{\mathrm{TOP}}$, for the VRC system and sum of the condensation pressure, $\mathrm{P}_{\mathrm{CHP}}$ and pressure increase over the compressor, $\Delta \mathrm{P}$, to the top pressure, $\mathrm{P}_{\mathrm{TOP}}$ for the $\mathrm{VRC}_{\Delta \mathrm{P}}$ system. Since the energy consumption changes linearly with the feed flow rate, and as the present work makes a comparison of the relative performances, the base case flow rate was taken to be $1.098 \times 10^{-4} \mathrm{kmol} \mathrm{s}^{-1}$. Also the column heat loss and the effect of such parameters as pressure increase across the compressor, the overall heat transfer coefficient of reboiler-condenser as an explicit function of Prandtl, Reynolds and Nusselt numbers which in turn depend on fluid properties are considered to account properly for variations in heat duty (Enweremadu, 2007; Enweremadu et al, 2009).

Table 1 shows that the VRC enables some energy savings when compared with $V_{R C}$. The $\mathrm{VRC}$ has a slightly lower compression ratio and consumes less energy than $\mathrm{VRC}_{\triangle \mathrm{P}}$ system. Although there was a marginal increase in $\Delta \mathrm{P}$, which increased the compressor power input slightly, the performances of the two systems differ greatly by $27.5 \%$. However, in addition to the pressure increase, the energy consumption appears to depend more on the rate of heat transfer in the reboiler. Hence the total energy consumption is indirectly related to column heat loss and pressure increase across the compressor through reboiler heat transfer and compressor power input respectively.

Also from Table 1, the heat transfer duties of the reboiler-condenser in terms of the overall heat transfer coefficient for the two systems show that the $\mathrm{VRC}_{\Delta \mathrm{P}}$ has a higher value when compared with the VRC system. This implies that the $\mathrm{VRC}_{\Delta \mathrm{P}}$ will require a smaller heat 


\begin{tabular}{|c|c|c|}
\hline Parameter & $\begin{array}{l}\text { Actual } \\
\text { column }\end{array}$ & $\begin{array}{l}\text { Control } \\
\text { column }\end{array}$ \\
\hline Compressor power input $(\mathrm{kW})$ & 0.518 & 0.495 \\
\hline Total energy consumption (KW) & 9.26 & 7.26 \\
\hline $\begin{array}{l}\text { Rate of column heat loss }(\mathrm{kW}) \text { : } \\
Q_{\text {loss }}=\frac{\left(T_{P}-T_{a m b}\right) 2 \pi P_{s} N}{\frac{\ln \left(r_{i n s} / r_{o}\right)}{K_{P} \cdot \frac{2 \pi P_{s} \cdot t_{i n s}}{\ln \left(1+\frac{2 t_{i n s}}{d_{o}}\right)}}+\frac{1}{\frac{K_{\text {ins }} \cdot N u}{d_{o}+2 t_{\text {ins }}} \cdot\left(\pi d_{\left.\text {ins }, m . P_{s}\right)}\right.}}+\frac{2\left(\mathrm{~T}_{\mathrm{P}}-\mathrm{T}_{\mathrm{amb}}\right) \pi r_{0}^{2}}{\frac{\operatorname{tins}}{\mathrm{K}_{\mathrm{p}}}+\frac{1}{h_{o}}}\end{array}$ & 2.6 & 0.7 \\
\hline $\begin{array}{l}\text { Overall heat transfer coefficient }\left(\mathrm{kW} / \mathrm{m}^{2} \mathrm{~K}\right) \text { : } \\
\frac{1}{U A_{H P C}}=\frac{1}{\frac{0.023 K_{m}}{d_{o_{e x}}}\left(\frac{\rho_{m} u d_{o_{e x}}}{\mu_{m}}\right)^{0.8}\left(\frac{C_{p m}}{K_{m}}\right)^{0.4}\left(\frac{\mu_{\text {wall }}}{\mu_{m}}\right)^{0.14}}+\frac{1}{0.555\left[\frac{\rho_{L}\left(\rho_{L}-\rho_{v}\right) K_{L}^{3} g h^{\prime}}{\mu_{L} d_{i_{e x}}\left(T_{C H P}-T_{\text {wall }}\right.}\right.}\end{array}$ & 1.4 & $\begin{array}{c}0.3 \\
(\mathrm{U}=\mathrm{Q} / \mathrm{A} \\
\Delta \mathrm{T})\end{array}$ \\
\hline $\begin{array}{l}\text { Reboiler heat transfer rate }(\mathrm{kW}) \text { : } \\
\mathrm{Q}_{\mathrm{reb}}=\mathrm{Dh}_{\mathrm{D}}+\mathrm{Bh}_{\mathrm{B}}+\mathrm{L}_{1} \mathrm{~h}_{\mathrm{LV}, \mathrm{e}}+\mathrm{Q}_{\text {losses }}-\mathrm{Fh}_{\mathrm{F}}-\mathrm{Q}_{1}-\mathrm{Q}_{2}\end{array}$ & 8.7 & $\begin{array}{c}6.8(10 \% \\
\text { of } \\
\text { reboiler } \\
\text { heat rate })\end{array}$ \\
\hline $\begin{array}{l}\text { Coefficient of performance: } \\
\text { COP }=\frac{Q_{H P C}+Q_{23}}{\dot{W}_{c p}}\end{array}$ & 5.85 & 6.15 \\
\hline $\begin{array}{l}\text { Condenser heat distribution factor: } \\
f=\frac{Q_{H P C}}{Q_{\text {reb }}}\end{array}$ & 0.3 & 0.5 \\
\hline Compression ratio & 1.22 & 1.12 \\
\hline Compressor displacement rate $\left(\mathrm{m}^{3} / \mathrm{s}\right)$ & $3.88 \times 10^{-3}$ & $3.74 \times 10^{-3}$ \\
\hline Compressor heat load rate $(\mathrm{kW})$ & 0.13 & 0.12 \\
\hline Vapour specific volume after compression $\left(\mathrm{m}^{3} / \mathrm{kg}\right)$ & 9.49 & 9.93 \\
\hline Temperature at compressor discharge $(\mathrm{K})$ & 395 & 390 \\
\hline Compressor volumetric efficiency & 0.749 & 0.756 \\
\hline Thermodynamic efficiency & 15.8 & 20.2 \\
\hline Reflux ratio & 5.033 & 7.5 \\
\hline
\end{tabular}

Table 1. Model results of the actual column and control column (Enweremadu, 2007; Enweremadu et al, 2008 \& 2009) 
transfer area which is economical in terms of material conservation. Also, with higher $U$, the $\mathrm{VRC}_{\Delta \mathrm{P}}$ will have a better performance.

The column heat losses for the two vapour recompression distillation columns are shown in Table 1. The heat losses in distillation columns with heat pumps have been assumed to correspond to around 3\% of the energy supplied to the reboiler (Danziger, 1979). Oliveira, Marques and Parise (2002) assumed it to be as high as 10\%. However, in this study, the heat exchanged by the distillation column with the surroundings is considered and its effect included in the balance equation (1). The results obtained for the $\mathrm{VRC}_{\Delta \mathrm{P}}$ showed a marked difference between the two systems.

A comparison of the main reboiler heat transfer rate for the two systems is presented in Table 1. It is evident that neglecting and /or assuming a value for column heat loss instead of determining it had a significant effect on the values of $Q_{\text {reb }}$ in both systems. The heat pump distribution factor, $\mathrm{f}$, for the $\mathrm{VRC}_{\Delta \mathrm{P}}$ system is 0.346 which is slightly less than that for the VRC system (0.451). Since low value of heat load taken by the heat pump, $\mathrm{f}$ implies lower thermal conductance, then the value of the heat transfer area for the $\mathrm{VRC}_{\Delta \mathrm{P}}$ system is smaller when compared to the VRC system. However, lower value of thermal conductance, $\mathrm{UA}$, for the $\mathrm{VRC}_{\Delta \mathrm{P}}$ system indicates that the VRC system will have a better performance.

The simulation results also show that the coefficient of performance and the thermodynamic efficiency of the $V_{R C}$ system is lower when compared to the VRC system. Fonyo and Benko (1998) have shown that the electrically-driven compression heat pump should work with a COP not lower than 3-5. The value of 5.85 obtained from this study has shown that although there is a decrease in the effectiveness of the $\mathrm{VRC}_{\Delta \mathrm{P}}$ system when compared with the VRC system with COP of 6.15 , it is within the acceptable range. This may be due to the fact that the compressor power input and the total energy consumption in the $\mathrm{VRC}_{\Delta \mathrm{P}}$ system is higher than in the VRC system.

\section{Conclusions}

From the outcome of the study, the following conclusions may be drawn:

1. Pressure increase across the compressor, $\Delta \mathrm{P}$ increases the compression ratio, the compressor power input, temperature in the heat pump reboiler-condenser while the compressor volumetric efficiency decreases. The effect of these is the reduction in the heat pump coefficient of performance and the use of a compressor of greater capacity.

2. Neglecting the effects of pressure increase across the compressor, $\Delta \mathrm{P}$ reduces the compression ratio and hence maximizes the energy efficiency. However, this leads to a substantial decrease in temperature in the heat pump reboiler-condenser. The overall effect of this is a decrease in the overall heat transfer coefficient, $U$ resulting in an increase in heat transfer area.

3. From the comparison between the $\mathrm{VRC}_{\Delta \mathrm{P}}$ and VRC systems, there was a profound difference in the overall heat transfer coefficient while the column heat loss was substantial.

The increase in the total energy consumption, reboiler heat transfer rate and the thermodynamic efficiency were appreciable, while there was only a marginal increase 
in the compressor power input resulting in a difference of $5.12 \%$ in the coefficient of performance between the $\mathrm{VRC}_{\Delta \mathrm{P}}$ and VRC systems.

4. Calculation of the column heat loss in contrast to the assumed value of certain percentage of the reboiler heat transfer rate gives a higher value resulting in higher energy consumption and lower thermodynamic efficiency.

\section{References}

Ackland, T. (1990). Physical Properties of Ethanol-Water Binary Mix. 20.07.2006, Available from http://www.homedistillers.org

AM Cola LLC (2005). EZChemDB Thermodynamic Properties Table for Ethanol

Braisher, M.; Gill, S.; Treharne, W.; Wallace, M. \& Winterburn, J. (2006). Design Proposal: Bio-ethanol Production Plant. 15.02.2007, Available from

http://www.ethanol.org

Brousse, E.; Claudel, B. \& Jallut, C. (1985). Modeling and Optimisation of the Steady Operation of a Vapour Recompression Distillation Column. Chemical Engineering Science, Vol. 40, No. 11, pp, 2073-2078, ISSN 0009-2509

Canales, E. \& Marquez, F. (1992). Operation and Experimental Results on a Vapor Recompression Pilot Plant Distillation Column. Industrial \& Engineering Chemistry Research, Vol. 31, pp. 2547 -2555, ISSN 0888-5885

Collura, M. \& Luyben, W. (1988). Energy - Saving Distillation Designs in Ethanol Production. Industrial \& Engineering Chemistry Research, Vol. 27, pp. 1686-1696, ISSN 0888-5885

Danziger, R. (1979). Distillation Column with Vapor Recompression. Chemical Engineering Progress Vol. 75, No. 9, pp. 58-64, ISSN 0360-7275

Emtir, M.; Miszey, P.; Rev, E. \& Fonyo, Z. (2003). Economic and Controllability Investigation and Comparison of Energy-Integrated Distillation Schemes. Chemical and Biochemical Engineering Quarterly. Vol. 17, No.1, pp. 31-42, ISSN 0352-9568

Enweremadu, C.(2007). Simulation of an ethanol-water distillation column with direct vapour recompression heat pump. PhD Thesis. Ladoke Akintola University of Technology, Ogbomoso, Nigeria

Enweremadu, C.; Waheed, M. \& Ojediran, J. (2008). Parametric study of pressure increase across a compressor in ethanol-water vapour recompression distillation, Scientific Research and Essay, Vol. 3, No.9, pp. 231-241, ISSN 1992-2224

Enweremadu, C.; Waheed, M. \& Ojediran, J. (2009). Parametric study of an ethanol-water distillation column with direct vapour recompression heat pump, Energy for Sustainable Development. Vol. 13, No. 2, pp. 96-105, ISSN 0973-0826

Enweremadu, C. \& Rutto, H. (2010). Investigation of heat loss in ethanol-water distillation column with direct vapour recompression heat pump, Proceedings of World Academy of Science, Engineering \& Technology 2010, International Conference on Thermal Engineering, pp. 69-76, ISSN 1307-6892, Amsterdam, The Netherlands, 28 - 30 September, 2010

Ferre, J.; Castells, F. \& Flores, J. (1985). Optimization of a Distillation Column with a Direct Vapor Recompression Heat Pump. Industrial and Engineering Chemistry Process Design and Development, Vol. 24, pp. 128-132, ISSN 0196-4305 
Fonyo, Z. \& Benko, N. (1998). Comparison of various heat pump-assisted distillation configurations. Transactions of the Institution of Chemical Engineers. Vol. 76, Part A, pp. 348-360, ISSN 0046-9858

Gani, R.; Ruiz, C. \& Cameron, I. (1986). A Generalised Model for Distillation Column I: Model Description and Applications. Computers \& Chemical Engineering, Vol.10, No.3, pp.181-198, ISSN 0098-1354

Gopichand, S.; Devotta, S.; Diggory, P. \& Holland, F. (1988). Heat Pump-Assisted Distillation VIII: Design of a System for Separating Ethanol and Water. International Journal of Energy Research, Vol.12, No. 1, pp.1-10, ISSN 0363-907X

Halvorsen, I. (2001). Minimum Energy Requirements in Complex Distillation Arrangements. Dr.Ing.Thesis, Department of Chemical Engineering, Norwegian University of Science and Technology. 20.10.2004, Available from http://www.chembio.ntnu.no/users/skoge/publications

Han, M.; Lin, H.; Yuan, Y.; Wang, D. \& Jin, Y. (2003). Pressure Drop for Two-phase Countercurrent Flow in a Packed Column with a Novel Internal. Chemical Engineering Journal. Vol. 94, pp. 179-184, ISSN 1385-8947

Hewitt, G.; Quarini, J. \& Morell, M. (1999). More Efficient Distillation. The Chemical Engineer, 21st October 1999

Holman, J. (2005). Heat Transfer, 9th Edition. McGraw-Hill Book Co., ISBN 0-07-029620-0, New York

Jorapur, R. \& Rajvanshi, A. (1991). Alcohol distillation by solar energy, ISES Solar World Congress Proceedings, Vol. I, Part II, pp. 772-777, Denver, Colorado, USA, August 19-21, 1991

Liu, X. \& Quian, J. (2001). Modelling, Control and Optimization of Ideal Internal Thermally Coupled Distillation Columns. Chemical Engineering \& Technology. Vol. 23, No. 3, pp. 235- 241, ISSN 1521-4125

Meili, A .(1990). Heat Pumps for Distillation Columns. Chemical Engineering Progress, pp. 60 65, June 1990, ISSN 0360-7275

Mori, H.; Ito, C.; Taguchi, K. \& Aragaki, T. (2002). Simplified Heat and Mass Transfer Model for Distillation Column Simulation. Journal of Chemical Engineering of Japan. Vol. 35, No.1, pp.100 - 106, ISSN 0021-9592

Muhrer, C.; Collura, M. \& Luyben W. (1990). Control of Vapor Recompression Distillation Columns. Industrial Engineering and Chemistry Research., Vol. 29, No. 1, pp. 59-71, ISSN 0888-5885

Null, H. (1976). Heat Pumps in Distillation. Chemical Engineering Progress, pp. 58 -64, July 1976, ISSN 0360-7275

Oliveira S.; Marques R. \& Parise, J. (2001). Modelling of an Ethanol - Water Distillation Column with Vapor Recompression. International Journal of Energy Research. Vol. 25, No. 10, pp. 845-858, ISSN 0363-907X

Oliveira, S.; Marques R. \& Parise, J. (2002). Modelling of an Ethanol - Water Distillation Column Assisted by an External Heat Pump. International Journal of Energy Research. Vol. 26, pp, 1055 - 1072, ISSN 0363-907X 
Olujic, Z.; Fakhri, F.; de Rijke, A.; de Graauw, J. \& Jansen, P. (2003). Internal Heat Integration - the key to an energy-conserving distillation column. Journal of Chemical Technology and Biotechnology. Vol. 78, pp, 241 - 248, ISSN1097-4660

Pfeffer, M.; Wukovits, W.; Beckmann, G. \& Friedl, A. (2007). Analysis and decrease of the energy demand of bioethanol production by process integration. Applied Thermal Engineering. Vol.27, No. , pp. 2657-2664, ISSN 1359-4311

Rajput, R. (2002). Heat and Mass Transfer. S.Chand and Co. Ltd., New Delhi, ISBN 81-219$1777-8$

Sloley, A. (2001). Energy Conservation Seminars for Industry: Texas Energy Conservation. Distillation Column Operations Manual. 16.11.2005, Available from http:/ /www.distillationgroup.com 


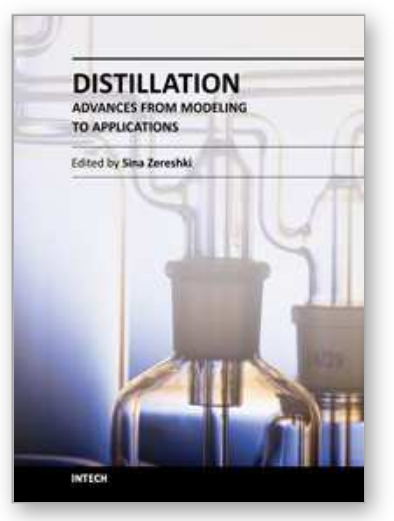

\author{
Distillation - Advances from Modeling to Applications \\ Edited by Dr. Sina Zereshki
}

ISBN 978-953-51-0428-5

Hard cover, 282 pages

Publisher InTech

Published online 23, March, 2012

Published in print edition March, 2012

Distillation modeling and several applications mostly in food processing field are discussed under three sections in the present book. The provided modeling chapters aimed both the thermodynamic mathematical fundamentals and the simulation of distillation process. The practical experiences and case studies involve mainly the food and beverage industry and odor and aroma extraction. This book could certainly give the interested researchers in distillation field a useful insight.

\title{
How to reference
}

In order to correctly reference this scholarly work, feel free to copy and paste the following:

Christopher Enweremadu (2012). Energy Conservation in Ethanol-Water Distillation Column with Vapour Recompression Heat Pump, Distillation - Advances from Modeling to Applications, Dr. Sina Zereshki (Ed.), ISBN: 978-953-51-0428-5, InTech, Available from: http://www.intechopen.com/books/distillation-advancesfrom-modeling-to-applications/energy-conservation-in-ethanol-water-distillation-column-with-vapourrecompression-heat-pump

\section{INTECH}

open science | open minds

\section{InTech Europe}

University Campus STeP Ri

Slavka Krautzeka 83/A

51000 Rijeka, Croatia

Phone: +385 (51) 770447

Fax: +385 (51) 686166

www.intechopen.com

\section{InTech China}

Unit 405, Office Block, Hotel Equatorial Shanghai

No.65, Yan An Road (West), Shanghai, 200040, China

中国上海市延安西路65号上海国际贵都大饭店办公楼 405 单元

Phone: +86-21-62489820

Fax: +86-21-62489821 
(C) 2012 The Author(s). Licensee IntechOpen. This is an open access article distributed under the terms of the Creative Commons Attribution 3.0 License, which permits unrestricted use, distribution, and reproduction in any medium, provided the original work is properly cited. 